Manuel Ugarte

\title{
EL DESTINO DE DOS RAZAS EN AMERICA
}

- 2 L Nuevo Mundo ofreció una oportunidad para que se renovaran y se pusiesen a prueba las dos grandes corrientes de pensamiento y de acción que atraviesan la historia en las épocas modernas.

Desde 1492 los descubridores españoles, los navegantes portugueses y los exploradores franceses representaron las inspiraciones meridionales, esencialmente latinas. Los colonos ingleses, que se instalaron un siglo más tarde en zonas primitivamente visitadas por aquéllos, fueron los pioneers de las inspiraciones nórdicas.

No hemos de juzgar comparativamente el valor de las dos fuerzas que se afrontaron. Parece evidente que, en sí, la latina era, intrínsecamente, superior. Pero, esencialmente especulativa, y limitada en su aplicación a núcleos reducidísimos en dilatadas comarcas habitadas por muchedumbres analfabetas, fué fácilmente sobrepasada por la anglo-sajona, más experimental y generalizada, desde los comienzos, de acuerdo con una concepción moderna de la vida. 
Cuando vamos a buscar, como quien remonta un río hasta el manantial, la causa de la situación actual de los dos grupos que se desarrollan en el Nuevo Mundo, lo que primero nos sorprende es la extrema facilidad con que, en un Continente y en una época que parecía pertenecer a los latinos, el ínfimo grupo inicial de anglo-sajones agiganta en pocos años su radio de acción, sus posiciones, sus recursos y su prestigio, mientras las inconmensurables comarcas dominadas por España, Francia y Portugal se anemian, pierden extensión, caen en el desorden o pasan a poder de otros países.

¿A qué atribuir la extraordinaria rapidez de esta suplantación?

Achacarla. a las excelencias de la diplomacia o a la destreza en el gobierno sería ya admitir una superioridad de maniobra en el grupo que sacó ventaja. Todo indica, desgraciadamente para nosotros, que además de estos factores de victoria existieron otras causas que determinaron una mayor eficacia práctica en los momentos en que actuaban y para el fin que perseguían.

Sería vano sostener hoy que la civilización latina dió en América mejor resultado que la civilización anglo-sajona. Los hechos están ahí, claros y patentes. Francia perdió el Canadá y la Luisiana y sólo conserva pequeñas posiciones en el Caribe. España-no hablemos ya del dominio directo, sino de la irradiación de su espíritu-vió naufragar extensiones cuantiosas. Bastaría citar La Florida y Puerto Rico, para atenernos sólo a lo oficialmente catalogado, sin aludir a las formidables zonas de influencia que se van ampliando día a día a expensas de lo que antes sólo fué animado por la civilización mediterránea.

El fenómeno es tan patente, que aún después de un siglo de vida autónoma la mayoría de nuestras 
Repúblicas no ha logrado valorizar las riquezas de su suelo, delimitar cabalmente sus fronteras, ni hacerse una idea clara de su destino, mientras los anglosajones, arrebatados en una ascensión maravillosa, han transmutado todos los valores, creando con el legado recibido formas inéditas de vida y de prosperidad.

Debemos los hombres del Sur considerar la situación sin engaños, sin timidez y sin miedo. Resulta pueril callar ante situaciones que son de dominio público y que no quedan suprimidas por el hecho de que finjamos ignorarlas. Con nuestra anuencia, o sin ella, seguirán las evidencias siendo inexorables. Hay que encararlas, pues, sin irritación y sin encogimiento, en el plano superior de las posibilidades políticas y de la lógica evolución de los pueblos.

Buscar excusas, es jugar con las palabras. Atribuir la situación en que se hallan nuestras repúblicas a la herencia española, equivale a rehuir las responsabilidades, arrojándolas sobre los muertos.

Nadie niega la disminución de fuerza y de prestigio que ha sufrido España, si comparamos su estado actual con las preeminencias fastuosas de otros tiempos. No hemos de discutir tampoco, por otra parte, las peculiares sui generis que llevaron al conquistador a dejar en América la marca de su individualismo anárquico. Estamos tan lejos de disimularnos cuál es el gusano roedor de la potencialidad española, como de negar el eclipse de su irradiación sobre el mundo.

Pero de aquí a atribuir a España nuestros errores, hay un abismo insalvable. Los que se lamentan de su herencia son prófugos de la nacionalidad y mediocres conocedores de su propia historia. Hacia 1810 quedó en el Sur una civilización que, en conjunto, podía ser equiparada a la que los anglo-sajones dejaron en el Norte en 1775 . No hay que extender hasta el pa- 
sado la virtud de las situaciones presentes dando por sentado que los Estados Unidos existieron siempre en su esplendor actual. Los sistemas implantados por la colonización desde Londres resultaban tan egoístas y excluyentes como los decretados desde Lisboa o Madrid. De no ser así, no se hubiera producido el movimiento separatista de las colonias anglosajonas. Los métodos liberales de colonización surgieron después de las lecciones recibidas en el Nuevo Mundo. Hoy mismo, si Inglaterra abandonase la isla de Jamaica, hallaríamos en esa isla un estado en algunos puntos igual y en otros inferior al que existía en Cuba en 1898 cuando se retiró España.

Aquilatando los hechos con serenidad, no se halla indicio de una inferioridad personal del español. Individualmente, éste conserva la eficacia social de los mejores tiempos. La prueba está al alcance de todos. Hasta el infinito se multiplica diariamente en nuestras repúblicas la aventura del que llega pobre de Galicia o de Asturias y se improvisa en pecos años fortuna cuantiosa, creando empresas que redundan en beneficio de la colectividad. Nunca se mostró el español menos apto que los hombres de otros países para prosperar en la tierra nueva.

Lo que ocurre con España es un fenómeno de desdoblamiento. Si la entidad está enferma, los componentes se hallan intactos. Todo ello tiene estrecha similitud con lo que pasa en la América Latina. En realidad, la disminución que comprobamos en torno no deriva de una inferioridad del hombre. Es resultado de formas erróneas de vida y de falsas direcciones éticas.

Si los trece estados anglo-sajones, que apenas ocupaban en 1776 una extensión de 1.000,000 de kilómetros cuadrados y apenas reunían una población de cuatro millones, dominan hoy, contando las zonas que según Moon están sujetas a su dependencia, 
sobre una extensión de doce millones de kilómetros cuadrados y reunen una población de 134 millones de habitantes, no es porque el anglo-sajón, étnica, humanamente, sea superior al neo-latino.

Lo que se puede conceder al abarcar la trayectoria de la marcha, antes y después del coloniaje, es que muchas de nuestras superioridades, reales o pretendidas, fueron un peso muerto que tuvimos que arrastrar. En la mayoría de los casos eran, como hemos tenido oportunidad de decirlo en otra ocasión, superioridades prescritas. Las excelencias ideológicas dieron lugar a desventajas materiales que, combinadas con la preeminencia absorbente de las direcciones contemplativas, con la educación empírica, con la fatiga transplantada del núcleo dominante, tenían que dar por resultado el desorden, la rémora, la inmovilidad.

No fueron los hombres, fueron los sistemas los que triunfaron o fracasaron. Lo que se puso a prueba fué la organización de los núcleos, las direcciones nacionales, sociales, culturales, las disciplinas colectivas, la concepción superior. Si los anglo-sajones lograron plenamente en la zona que dependió de su jurisdicción los propósitos iniciales, y si los latinos o neo-latinos, no lo consiguieron en las tierras del Sur, si hemos quedado rezagados, si nuestra América se adelanta hacia una situación disminuida que presagia dolorosas abdicaciones, no es, repetimos, porque los hombres del Norte fuesen superiores a los del Sur, sino porque, siendo indispensable para realizar el intento una brújula y un programa, los primeros tuvieron esa brújula y ese programa y los segundos no.

Los campos vírgenes, las riquezas intactas, la fecundidad delirante de un Continente pródigo de todos los elementos de triunfo, y hasta la raza renovada al transplantarse por la comunión con las zonas recién 
descubiertas, favorecían igualmente el advenimiento de dos grandes conjuntos, no ya equivalentes sino superiores por la extensión y el número de habitantes a los núcleos originarios europeos. Pero anglo-sajones y latinos habían contraído el compromiso de sacarse la chaqueta y de decir: "Ahora vamos a hacer una nación.» Si sólo los primeros cumplieron plenamente ese propósito, es debido a circunstancias que trataremos de sintetizar en ocasión posterior.

Al separarse irrevocablemente de la metrópoli, la primera necesidad, lo mismo para los anglo-sajones que para los latinos, residía en crear desde los cimientos una existencia propia, llenando cuatro condiciones primordiales:

a) Poner la autonomía del conglomerado a cubierto de todas las contigencias exteriores;

b) Afianzar de una manera irrevocable la unidad interior de ese conjunto;

c) Asegurar la convivencia armónica y el bienestar de todos los habitantes, y

d) Valorizar los recursos de la región para confirmar la automomía política con la autonomía económica.

Al sintetizar lo que hiceron ambos grupos para lograr este fin mantendremos la clasificación $a, b$, $c, d$, para facilitar la confrontación de los dos esfuerzos.

Los anglo-sajones:

a) Previnieron, en el origen mismo de su nacimiento como nación, todo peligro de ingerencia extraña, llegando hasta estipular que las tropas de Lafayette se limitarían a ayudar a la independencia, sin intentar reconquistar el Canadá, que Francia acababa de perder por aquel tiempo. A medida que se fueron robusteciendo redondearon sus fronteras, con un criterio a la vez comercial y estratégico, aprovechando las oportunidades que ofrecían las querellas o las debilidades de los demás y empleando siempre el 
procedimiento adecuado a las circunstancias: adquisición, captación, conquista, etc. Así engrosaron el primitivo núcleo con la Luisiana francesa, La Florida española, la California mexicana, la Alaska rusa, obedeciendo al método implacable y a la vasta concepción del futuro que debía completarse en los últimos tiempos (pasando de la defensiva a la ofensiva), con el predominio sobre el mar Caribe y la apertura del canal de Panamá que auguran una expansión indefinida hacia el Sur.

b) Ahogaron irrevocablemente todo intento de segregación, acabando (como sanción) de una manera inapelable con la guerra separatista de 1861, y respetando (como medida preventiva) el sentimiento de cada uno de los Estados (constituciones divergentes, leyes de interés local, etc.) para mantenerlos sin violencia dentro de la orquestación superior que debía dar a todos voz eficaz y autoridad indiscutida en el mundo.

c) Adoptaron normas de vida que ofrecían a los ciudadanos idénticas posibilidades de desarrollo y ascensión, aboliendo en la realidad, no en el papel, los privilegios. Con excepción del núcleo africano que aún después de abolida la esclavitud arrastra una vida miserable, los componentes de la nueva nación tuvieron un punto de partida equivalente. Sin preocupaciones de abolengo o de riqueza, todos los hombres pudieron aspirar a las situaciones más altas en el gobierno, en la fortuna, en la influencia social, creando un cuerpo constantemente renovado, por el cual circuló siempre sangre fresca. El fenómeno de la hegemonía plutocrática que se agudizó en las postrimerías del siglo XIX nada tiene de común con las oligarquías de nuestra América puesto que está basado en el bien que se adquiere y no en el bien que se hereda. Por otra parte, pasando al orden espiritual, los Estados Unidos renunciaron a las estériles luchas 
confesionales, imponiendo la tolerancia entre las diversas interpretaciones deístas y haciendo de la religión un simple problema individual.

d) Consagraron su esfuerzo mayor a la tarea de valorizar los recursos del suelo y subsuelo, creando la prosperidad colectiva, de acuerdo con métodos tan científicos como originales. Al trocarse la colonia en nación, era evidente que los sistemas debían tender a transformar la organización en favor de los de afuera en una organización en favor de los de adentro, imponiendo, con la autonomía económica, la movilización de las fuerzas de la nación en favor de la nación misma. Ningún pueblo realizó esta metamorfosis con tan estupenda rapidez, ni con tan maravillosa fortuna. Bastaron pocos años para que la colectividad se colocase en condiciones de bastarse a sí misma. Sin detenerse un instante, pasó después como en el acápite $a$, de la defensiva a la ofensiva, inundando con sus productos y su irradiación comercial a los mismos pueblos que antes fueron sus mentores o proveedores. En menos de un siglo la antigua colonia se había transformado en una nueva Metrópoli apta para superdirigir a su vez y hasta para sobreponerse a Europa y disputar a Inglaterra el dominio de los mares.

¿Qué hicieron mientras tanto los latino-americanos? Siguiendo el mismo método, pasemos revista a la acción desarrollada en el Sur:

a) Desdeñando la evidencia elemental de que los elementos disgregados del tronco inicial sólo podían , realizar sus destinos cohesionados dentro de su tradición, su lengua, su cultura y su filiación racial, los latinoamericanos se perdieron en querellas locales y se dejaron deslumbrar por ambiciones pequeñas. Así vimos surgir una veintena de repúblicas empeñadas en rivalidades suicidas. Con algo de la inconsciencia de las monarquías balcánicas (estas 
tienen por lo menos la excusa de antecedentes disímiles) desatendieron la urgencia de prevenir las avideces extrañas. El sentimiento de auto-defensa se fué atrofiando, hasta el punto de ser pospuesto en ciertas zonas a los odios de partido. Y así nació una constelación de satélites prometidos al protectorado más o menos sutil de las grandes naciones que se llevan en silencio los provechos, dejando a veces como limosna la ilusión de la libertad.

b) Lejos de tender por lo menos a la unión moral del primitivo conjunto desmigajado, los latino-americanos, inventaron, dentro y fuera de cada república, los pleitos más complicados. El localismo, signo siempre de crisis o de debilidad en los pueblos, llevó a cada república a fabricarse una historia aparte, olvidando que sólo juntas tenían fuerza suficiente para perpetuar un ideal.

c) Mantuvieron en la ignorancia y en la servidumbre al indígena, falseando la letra y el espíritu de las Constituciones. Buena o mala, la promiscuidad racial es entre nosotros un hecho que no es posible tergiversar. Si consideramos en bloque a la América Latina, encontramos que el 70 por ciento por lo menos de sus habitantes es esencialmente indígena. Al separarse de la metrópli, no quedaba más recurso que organizar la masa conjunta. Por otra parte, la independencia se conquistó con el esfuerzo concordante de criollos de todas las sangres. Cada uno de esos grupos dió al movimiento hombres útiles, atestiguando que todos eran aptos para colaborar en el encumbramiento colectivo. Empapadas en ideas retrógadas, que las llevaron hasta intentar la creación imposible de monarquías o de imperios, las precarias minorías que se atribuían la direcciốn del movimiento desatendieron todo contacto con la masa. Así surgieron los grupos de eficacia hereditaria, mitad aristocráticos, mitad plutocráticos, que se congregaron alre- 
dedor de determinados sistemas de gobierno y asumieron la representación exclusiva de las incipientes naciones, olvidando que la independencia sólo puede existir donde existe la plena nacionalidad.

d) En vez de enaltecer el trabajo, la iniciativa, el esfuerzo que debía hacer brotar chorros de prosperidad de la tierra nueva, las patrias en formación heredaron del régimen colonial una pseudo-élite inactiva y un proletariado amorfo. Del colonialismo político pasamos al colonialismo económico. Mientras los grupos preeminentes se entregaban en las ciudades a la vanidad social o a la politiquería egoísta, las riquezas, nacionales in nomine, fueron explotadas y contraloreadas por organismos ajenos a nuestro conjunto. Tal fué el origen de la futura sujeción. Lo que un momento pareció provisional, se convirtió en definitivo. El Estado vivió de las rentas de aduanas; los favorecidos del régimen, del empleo o la jubilación. Y como los valores reales del país pasaban a manos extranjeras, quedó empeñado el porvenir.

Pero esta amarga situación, que se atenúa o se agrava según las zonas, no implica un fracaso de la latinidad en América, ni establece en ninguna forma la inferioridad de la civilización mediterránea. Sólo atestigua, en realidad, el empirismo de ciertas directivas y el error de los grupos que asumieron las funciones del gobierno. Si toda iniciativa lleva entre nosotros una marca importada, si cuanto vivifica la tierra nueva está accionado desde lejos y deja sus beneficios fuera de la colectividad, si nos desangramos en beneficio de las naciones mayores, es porque subsiste todavía entre nosotros, en sus engranajes básicos, la organización colonial, y porque no ha surgido todavía uno de esos movimientos unánimes que imponen a los espíritus y a la naturaleza misma una vibración renovadora y fecunda.

Los Estados Unidos realizaron el ideal de un pueblo Atenea.-17 
joven levantado por una civilización nueva. Los latino-americanos somos un pueblo joven también, pero agobiado por prejuicios, fórmulas o concepciones caducas. Los primeros crearon vida propia, los segundos prolongamos modalidades en desuso. No se puede hablar de colectividades enfermas, sino de conjuntos anestesiados. Bastaría determinar una remoción en los métodos y en las inspiraciones, ajustando nuestra vida a ritmos nuevos, para hacer surgir en el Sur, aunque sea con atraso y desventaja en los comienzos, todo lo que ha quedado detenido

o inutilizado. Sólo falta un soplo que anime los nacionalismos y restablezca la pulsación continental.

Exclusivo para Atenea en Chile. 